\title{
Environmental photocatalytic processes with POM. The photodecomposition of atrazine and photoreduction of metal ions from aqueous solutions
}

\author{
A. Hiskia, ${ }^{1}$ A. Troupis, ${ }^{1,2}$ and E. Papaconstantinou ${ }^{1}$ \\ ${ }^{1}$ Institute of Physical Chemistry, NCSR Demokritos, Athens, Greece \\ ${ }^{2}$ National Technical University of Athens, Chemical Engineering Department, Athens, Greece
}

\begin{abstract}
Polyoxometalate anions (POM), resulting from the condensation of tungstate anions in strongly acidified solutions, can absorb efficiently light in the UV-near Vis region.The produced excited state is a very powerful oxidative reagent which can, mainly via $\mathrm{OH}$ radical attack, oxidize and mineralize a great variety of organic pollutants in aqueous solutions, while the photocatalytic circle is closed by reoxidation of the reduced POM, mainly, by $\mathrm{O}_{2}$. Metal ions can also serve as oxidants and close the photocatalytic cycle. In the process metal ions are reduced, precipitated and removed from the solution. Thus photocatalytic treatment for decontamination of waste waters from both organic and inorganic pollutants (metal ions) can be, in principle, achieved.
\end{abstract}

$$
\begin{aligned}
& \mathrm{POM}+\mathrm{S} \stackrel{h v}{\longrightarrow} \mathrm{POM}_{\text {red }}+\mathrm{S}_{\mathrm{OX}}, \\
& \mathrm{POM}_{\text {red }}+\mathrm{M}^{\mathrm{n}+} \longrightarrow \mathrm{POM}+\mathrm{M}_{\text {red }} .
\end{aligned}
$$

Atrazine, a widely used herbicide with s-triazine structure, is photodecomposed to cyanuric acid in presence of $\mathrm{SiW}_{12} \mathrm{O}_{40}{ }^{4-}$ in aqueous solutions. However, no precipitation of metal ions is obtained when atrazine is the sole organic substrate in aqueous solutions. The low solubility of atrazine produces insufficient concentration of reduced POM to cause precipitation.

\section{INTRODUCTION}

Polyoxometalates (POM) is a large category of metal oxygen cluster anions with well defined structures and properties, of diversified interest. Their redox chemistry is characterized by their ability to act as multielectron relays. POM have been termed soluble anodes and indeed they behave so under irradiation at the $\mathrm{O} \longrightarrow \mathrm{M}$ CT band (near visible and UV area), oxidizing a great variety of organic compounds [1]. The oxidation leads to the mineralization of organic compounds and for that matter organic pollutants in aqueous solutions [2]. The mechanism seems to be mainly via the formation of the highly oxidizing $\mathrm{OH}$ radicals from the reaction of the excited POM with $\mathrm{H}_{2} \mathrm{O}$. In the process electrons accumulate on POM driving the redox potential to more negative values, until a species in solution is able to accept the electrons. Thus, now it can be said that they are converted to soluble cathodes, able to reduce a diversified number of chemicals. The nature of POM and the degree of reduction reflects their reducing capability. Thus $\mathrm{H}^{+}$have been reduced to $\mathrm{H}_{2}$, nitrobenzene to aniline, dioxygen to $\mathrm{O}_{2}{ }^{-}$etc.

This paper presents an overall view of the ability of POM to:

(a) Mineralize (to $\mathrm{CO}_{2}, \mathrm{H}_{2} \mathrm{O}$ and inorganic anions) a great variety of organic pollutants and (b) to cause, at the same time, reduction (recovery) of metal ions from aqueous solutions.

It also presents: (c) the photodecomposition of atrazine in connection with the reduction of various metal ions.

\section{EXPERIMENTAL}

Aqueous solution of the organic substrate $(2,4$ dichlorophenol $5 \times 10^{-4} \mathrm{M}$ or atrazine $7 \times 10^{-5} \mathrm{M}$; $4 \mathrm{ml})$ containing catalyst $\left(\mathrm{H}_{3} \mathrm{PW}_{12} \mathrm{O}_{40}\right.$ or $\mathrm{K}_{4} \mathrm{SiW}_{12} \mathrm{O}_{40}$ $\left.7 \times 10^{-4} \mathrm{M}\right)$ and metal ions $\left(\mathrm{Ag}^{+}, \mathrm{Cu}^{2+}, \mathrm{Ni}^{2+}\right.$ or $\mathrm{Pd}^{2+}$ $\left.1.2 \times 10^{-3} \mathrm{M}\right)$ was added in a spectrophotometer cell (1 cm path), deaerated with Ar and covered with a cerum cap. The $\mathrm{pH}$ of the solution was 1 for $\mathrm{H}_{3} \mathrm{PW}_{12} \mathrm{O}_{40}$ or 5.5 for $\mathrm{K}_{4} \mathrm{SiW}_{12} \mathrm{O}_{40}$. Photolysis was performed with an Oriel $1000 \mathrm{~W}$ Xe lamp equipped with a cool water circulating filter to absorb the near IR radiation and a 345 or $320 \mathrm{~nm}$ cut off filter to avoid direct photolysis of substrates. The photocatalytic process was followed by monitoring the concentration of:

a) The organic substrates and intermediates with HPLC reverse phase. The decay of the substrate and the production of intermediates were monitored by HPLC-UV consisted of a Waters Model 600E pump associated with a Waters Model 600 gradient controller, a Rheodyne Model 7725i sample injector equipped with 
$20 \mu \mathrm{l}$ sample loop, a reversed-phase (RP) $\mathrm{C}_{18}$ analytical column by Phase Sep $(25 \mathrm{~cm} \times 4.6 \mathrm{~mm}$ I.D., $5 \mu \mathrm{m})$ and Waters Model 486 tunable absorbance detector controlled by the Millenium (Waters) software. Isocratic phase program performed for the determination of atrazine and intermediate photolysis products, was acetonitrile-water (50:50, v/v), at a flow rate of $1.0 \mathrm{ml} / \mathrm{min}$. The wavelength used was $225 \mathrm{~nm}$ for the determination of atrazine, CIAT, CAET and CAAT, b) metal ions with Flame Atomic Absorption Spectrometry and

c) the reduced catalyst, UV/Vis-spectroscopically (750 nm), by means of a HITACHI U-2000 spectrophotometer.

\section{RESULTS AND DISCUSSION}

3.1. Overview of photodecomposition of organic substrates and metal recovery upon photolysis of aqueous solutions in the presence of POM. Excitation of POM at the $\mathrm{O} \rightarrow \mathrm{M}$ CT band (near visible and UV area) leads, in reality, to electron $\left(\mathrm{e}^{-}\right)$hole $\left(\mathrm{h}^{+}\right)$separation

$$
\mathrm{POM} \stackrel{h v}{\rightleftarrows} \mathrm{POM}\left(\mathrm{h}^{+}+\mathrm{e}^{-}\right)
$$

in analogy to metal oxide particulates (semiconductors).

The generated photoholes are powerful oxidizing species that either directly or indirectly (through formation of $\mathrm{OH}$ radicals) oxidize a great variety of organic compounds and for that matter organic pollutants. Direct oxidation

$$
\begin{aligned}
& \operatorname{POM}\left(\mathrm{h}^{+}+\mathrm{e}^{-}\right)+\mathrm{S} \\
& \quad \longrightarrow \operatorname{POM}\left(\mathrm{e}^{-}\right)+\mathrm{S}^{+} \quad \text { (oxidation products) }
\end{aligned}
$$

Indirect oxidation

$$
\begin{aligned}
& \mathrm{POM}\left(\mathrm{h}^{+}+\mathrm{e}^{-}\right)+\mathrm{H}_{2} \mathrm{O} \longrightarrow \operatorname{POM}\left(\mathrm{e}^{-}\right)+\mathrm{OH}+\mathrm{H}^{+} \\
& \mathrm{OH}+\mathrm{S} \longrightarrow \text { oxidation products. }
\end{aligned}
$$

The photodecomposition of organic compounds leads, in most cases, to mineralization, i.e., formation of $\mathrm{CO}_{2}$, $\mathrm{H}_{2} \mathrm{O}$ and inorganic anions.

So far a great variety of organic pollutants (such as phenols, halophenols, aromatic hydrocarbons, aliphatic compounds etc) have been shown to undergo mineralization upon photocatalytic treatment in the presence of POM [2].

Typical photodecompositions of organic pollutants are shown in Figure 1 [3]. Characteristic photodecomposition of organic substrate (lindane) and gradual development of $\mathrm{CO}_{2}$ and inorganic anions are shown in Figure 2 [3].

A general scheme of photodecomposition of 2,4 dichlorophenol, that seems to work for both POM

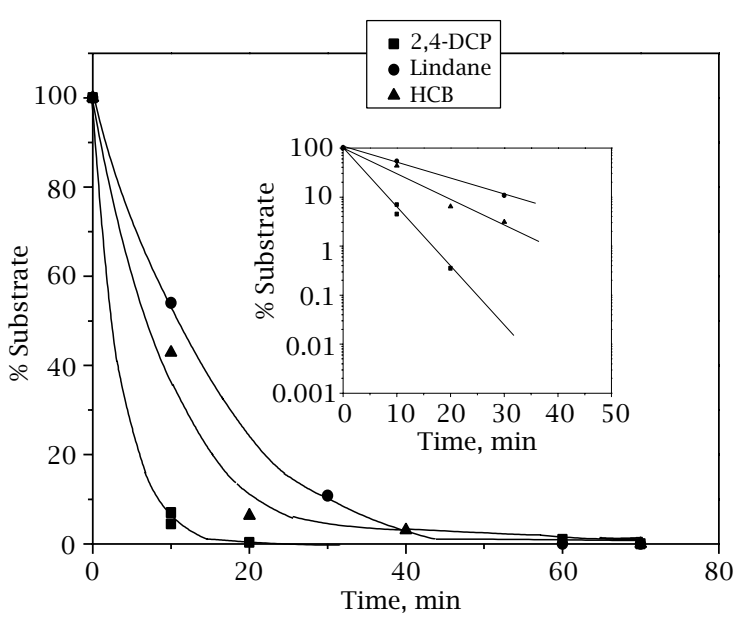

Figure 1. Photodegradation of 2, 4 Dichlorophenol $4 \times$ $10^{-4} \mathrm{M}$, lindane $3.7 \times 10^{-5} \mathrm{M}$ and partially dissolved, $\mathrm{HCB}$ $7.0 \times 10^{-6} M(\approx 2 \mathrm{ppm})$, upon photolysis of oxygenated aqueous solutions $\left(0.1 \mathrm{MHClO}_{4}\right)$ in presence of $\mathrm{PW}_{12} \mathrm{O}_{40}{ }^{3-}$ $7 \times 10^{-4} \mathrm{M} . \mathrm{T} \cong 20^{\circ} \mathrm{C}$. Insert: Pseudo first-order diagrams for the decomposition of the substrates. The scattered results with $\mathrm{HCB}$ are in accordance with the partial dissolution of substrate. (Reprinted from reference [3].)

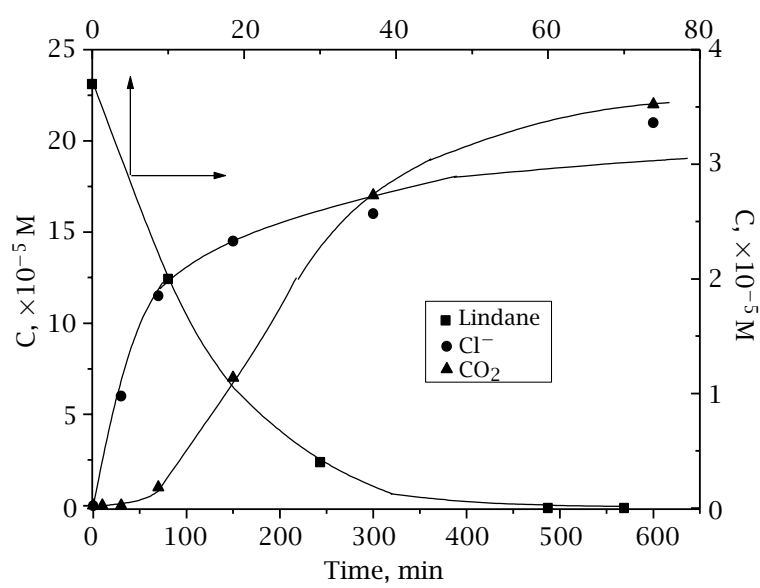

Figure 2. Formation of $\mathrm{CO}_{2}, \mathrm{Cl}^{-}$and decay of Lindane, $3.7 \times$ $10^{-5} \mathrm{M}$ upon photolysis of aqueous oxygenated solution in presence of $\mathrm{PW}_{12} \mathrm{O}_{40}{ }^{3-}$. Catalyst $7 \times 10^{-4} \mathrm{M}$, $\mathrm{pH} 1\left(\mathrm{HClO}_{4}\right)$; $\mathrm{T} 20^{\circ} \mathrm{C} ; \lambda>320 \mathrm{~nm}$. (Reprinted from reference [3].)

and metal oxide particulates $\left(\mathrm{TiO}_{2}\right)$ is presented below (Scheme 1). In the absence of an electron withdrawing species the solution is colored blue from the reduced POM. Figure 3 shows the characteristic development of the blue color of the one-equivalent reduced tungstosilicate $\left(\mathrm{SiW}_{12} \mathrm{O}_{40}{ }^{5-}\right)$ indicating the concomitant oxidation of the organic substrate upon photolysis of $\mathrm{SiW}_{12} \mathrm{O}_{40}{ }^{4-}$ in the presence of atrazine.

Key reactions in the photocatalytic treatment with $\mathrm{POM}$ is the reoxidation (regeneration) of catalyst that 


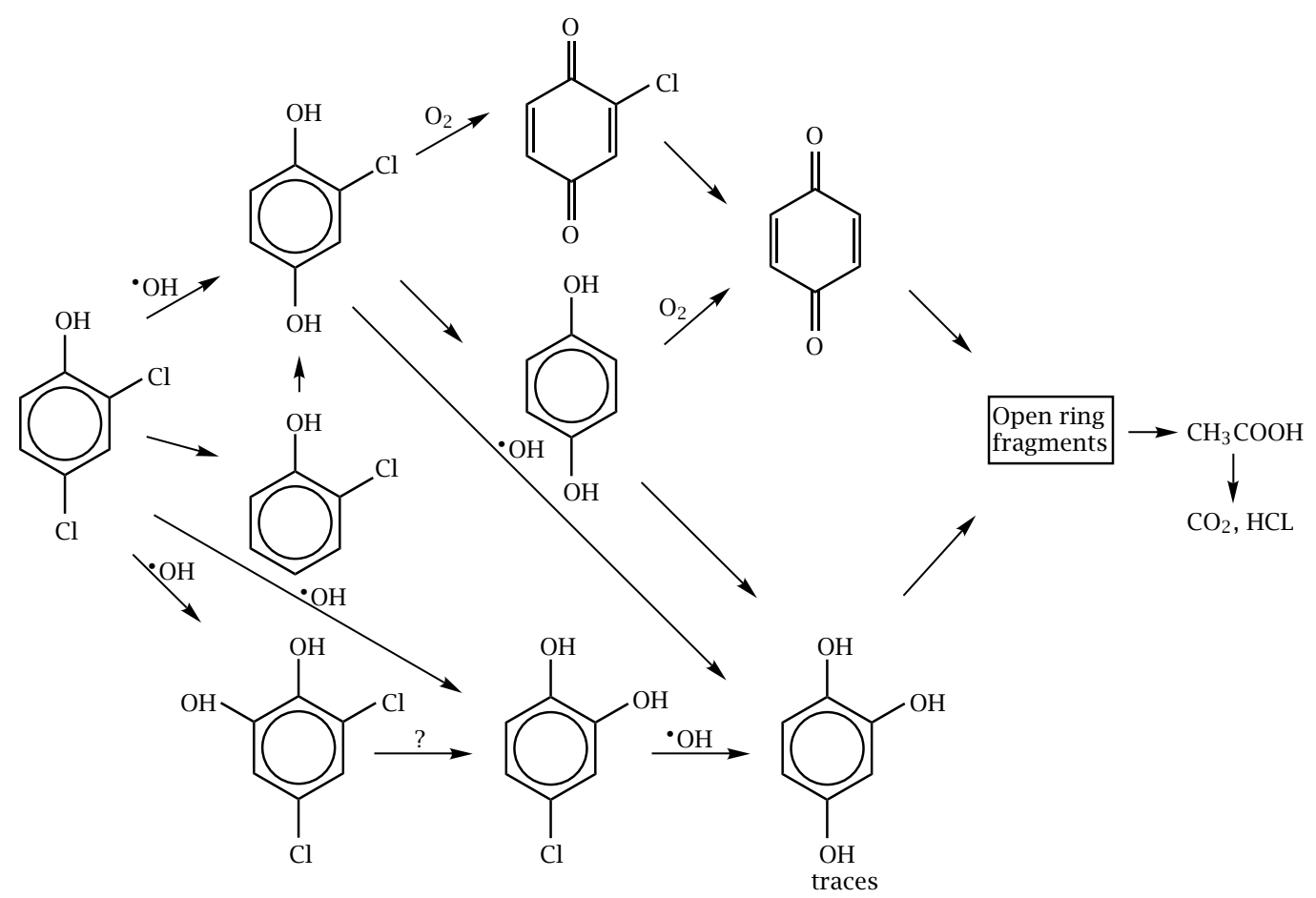

Scheme 1. Photodegradation pathway according to the common intermediates found in the photocatalytic decomposition of 2, 4-dichlorophenol by both systems. (Reprinted from reference [2].)

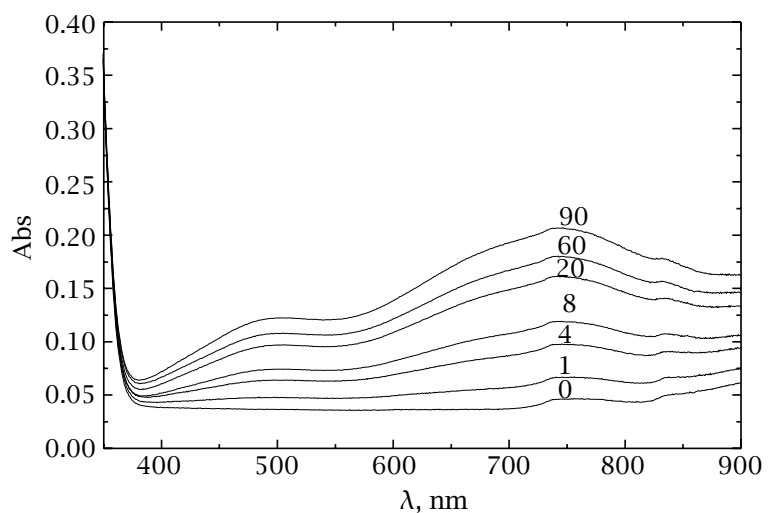

Figure 3. Gradual development of the characteristic blue colour of the one-electron reduced 12-tungstosilicate, $\mathrm{SiW}_{12} \mathrm{O}_{40}{ }^{5-}$, upon photolysis $(\lambda>320 \mathrm{~nm})$ of deaerated aqueous solution $\left(\mathrm{pH} 5.0, \mathrm{HClO}_{4}\right)$ of $\mathrm{SiW}_{12} \mathrm{O}_{40}{ }^{4-}(7 \times$ $\left.10^{-4} \mathrm{M}\right)$, in the presence of atrazine $\left(7 \times 10^{-5} \mathrm{M}\right)$. Time (min) is indicated on spectra.

closes the photocatalytic cycle [1],

$$
\operatorname{POM}\left(\mathrm{e}^{-}\right)+\text {oxidant } \longrightarrow \mathrm{POM}
$$

which is shown in Scheme 2.

Dioxygen is the most effective oxidant, whereas other oxidants can serve the same purpose [4].

Recently we have demonstrated the ability of photoreduced POM to be oxidized by metal ions

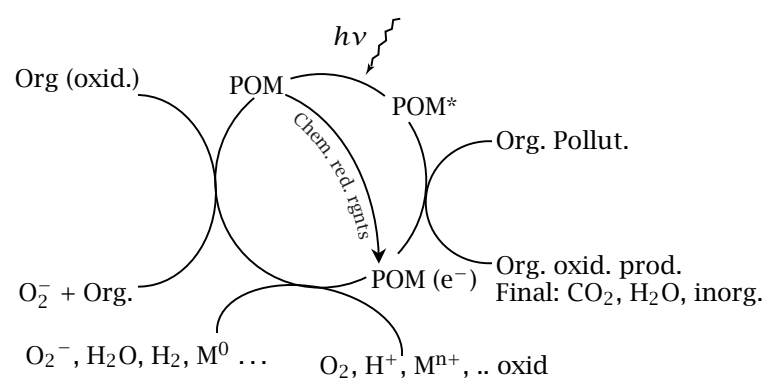

Scheme 2. The photocatalytic cycle describing the reactions involved in the presence of POM.

$$
\operatorname{POM}\left(\mathrm{e}^{-}\right)+\mathrm{M}^{\mathrm{n}+} \longrightarrow \mathrm{POM}+\mathrm{M}^{(\mathrm{n}-1)+} .
$$

The above redox process depends on the reducing ability and the degree of reduction of POM, the oxidizing ability of $\mathrm{M}^{\mathrm{n}+}$ and to a lesser extent on the nature of organic substrate. Thus, several metal ions are reduced to lower oxidation states and many, depending on conditions, are recovered (precipitate out) as $\mathrm{M}^{0}$ [5].

Thus, photolysis of an aqueous solution POM/S/ $\mathrm{M}^{\mathrm{n}+}$ [where POM $=\mathrm{PW}_{12} \mathrm{O}_{40}{ }^{3-}, \mathrm{S}=$ organic substrate (for instance 2,4 dichlorophenol) and $\mathrm{M}^{\mathrm{n}+}=$ metal ions] reduces selectively silver or palladium, while it does not affect $\mathrm{Ni}^{2+}$, as shown in Figure 4. Copper is also 


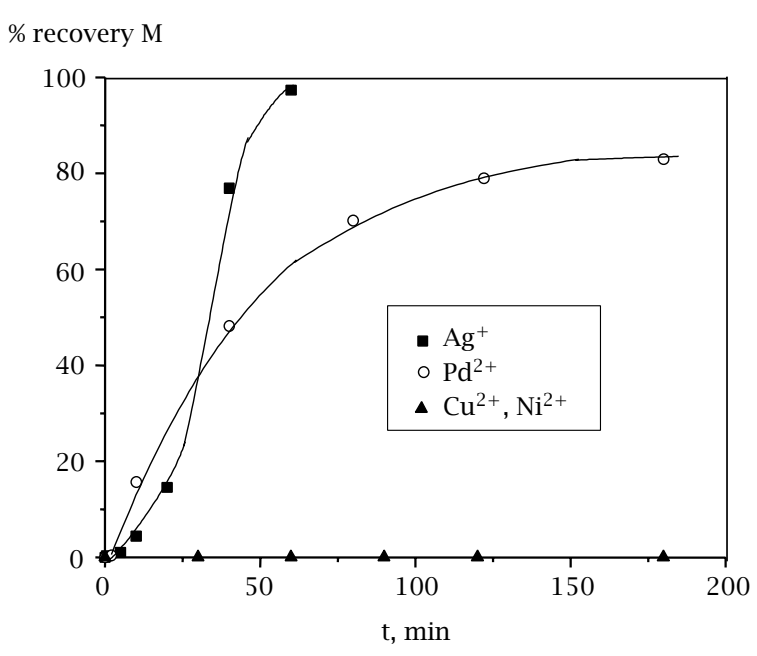

Figure 4. Recovery of metal ions during photolysis of an aqueous solution containing $\mathrm{H}_{3} \mathrm{PW}_{12} \mathrm{O}_{40} 0.7 \mathrm{mM}, 2,4$ DCP $1 \mathrm{mM}$ and $\mathrm{M}^{\mathrm{n}+} 1.2 \mathrm{mM}$. [pH $\left.1\left(\mathrm{HClO}_{4}\right), \lambda>345 \mathrm{~nm}, \mathrm{~T} 20^{\circ} \mathrm{C}\right]$. (Reprinted from reference [5].)

recovered when increasing the concentration of the organic substrate (2,4 dichlorophenol or propan-2-ol) by ten times.

\subsection{Photodecomposition of atrazine in the pres-} ence of $\mathrm{SiW}_{12} \mathrm{O}_{40}{ }^{4-}$ or $\mathrm{H}_{2} \mathrm{~W}_{12} \mathrm{O}_{40}{ }^{6-}$ and $\mathrm{M}^{\mathrm{n}+}$. In order to combine the ability of POM compounds to reduce metal ions with their oxidizing ability to mineralize organic pollutants, atrazine was used as organic substrate and its photocatalytic degradation in the presence of metal ions was examined.

Using $\mathrm{SiW}_{12} \mathrm{O}_{40}{ }^{4-}$ as photocatalyst atrazine disappeared within a few hours of photolysis $(\lambda>320 \mathrm{~nm})$ of deaerated solution, whereas the process was considerably slower with $\mathrm{H}_{2} \mathrm{~W}_{12} \mathrm{O}_{40}{ }^{6-}$, as shown in Figure 5. Notice that $\mathrm{SiW}_{12} \mathrm{O}_{40}{ }^{4-}$ photocatalyst is a much stronger oxidant than $\mathrm{H}_{2} \mathrm{~W}_{12} \mathrm{O}_{40}{ }^{6-}$, as the corresponding redox potentials for 1-electron reduction are 0.057 and $-0.337 \mathrm{~V}$ vs NHE, respectively.

Figure 6 shows the effect of $\mathrm{Cu}^{2+}, \mathrm{O}_{2}, \mathrm{Ni}^{2+}$ or absence of oxidant in the photodecomposition of atrazine using $\mathrm{SiW}_{12} \mathrm{O}_{40}{ }^{4-}$. It can be seen that introduction of $\mathrm{Ni}^{2+}$ ions in the system didn't affect the degradation rate of atrazine. On the contrary, addition of $\mathrm{Cu}^{2+}$ ions or, even more, $\mathrm{O}_{2}$ in the solution increased the degradation rate of atrazine.

In parallel, thermal experiments have shown that $\mathrm{Ni}^{2+}$ ions didn't change the concentration of the reduced catalyst, $\mathrm{SiW}_{12} \mathrm{O}_{40}{ }^{5-}$, in contrast with $\mathrm{Cu}^{2+}$ or $\mathrm{O}_{2}$ which reacted immediately with $\mathrm{SiW}_{12} \mathrm{O}_{40}{ }^{5-}$ and decolorised the solution.

Thus, by using better oxidizing reagents for reoxidation of the reduced POM, reaction (2) is accelerated and more catalyst in the oxidized form is available to absorb

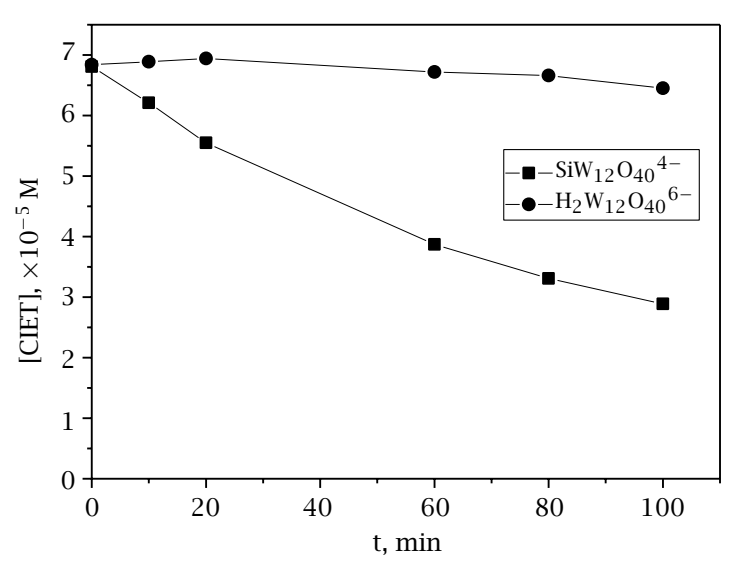

Figure 5. Photocatalytic degradation of atrazine in deaerated solution containing substrate $7.0 \times 10^{-5} \mathrm{M}(15 \mathrm{ppm})$, $\mathrm{SiW}_{12} \mathrm{O}_{40}{ }^{4-}$ or $\mathrm{H}_{2} \mathrm{~W}_{12} \mathrm{O}_{40}{ }^{6-}(0.7 \mathrm{mM})(\mathrm{pH} 5.0, \lambda>320 \mathrm{~nm})$.

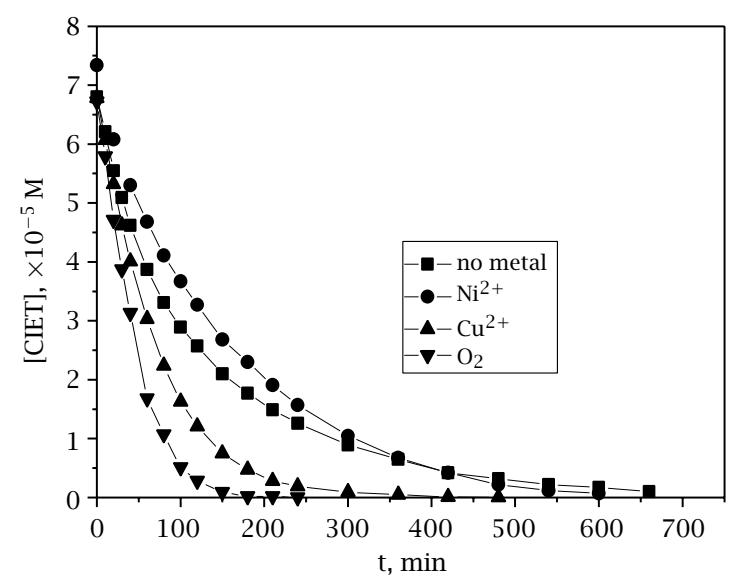

Figure 6. Photocatalytic degradation of atrazine in the presence of $\mathrm{SiW}_{12} \mathrm{O}_{40}{ }^{4-}(0.7 \mathrm{mM})$. Initial concentration of substrate $7.0 \times 10^{-5} \mathrm{M}(15 \mathrm{ppm})$, $\mathrm{pH} 5.0, \lambda>320 \mathrm{~nm} ; 4 \mathrm{ml}$ of deaerated solution containing a) no metal, b) $\mathrm{Ni}^{2+} 1.2 \mathrm{mM}$, c) $\mathrm{Cu}^{2+} 1.2 \mathrm{mM}$ or d) dioxygen saturated solution.

light and oxidize atrazine; meaning a faster process for the photocatalytic degradation of atrazine is achieved.

We have shown [6] that photolysis of aqueous solutions of 2-chloro-4-(isopropylamino)-6-(ethylamino)s-triazine (atrazine, CIET) in the presence of $\mathrm{SiW}_{12} \mathrm{O}_{40}{ }^{4-}$ leads, through a series of intermediates to cyanuric acid (2,4,6-trihydroxy-s-triazine, not shown in Scheme 3 below). The intermediates [2-chloro-4(isopropylamino)-6-amino-s-triazine (CIAT), 2-chloro-4amino-6-(ethylamino)-s-triazine (CAET) and 2-chloro4,6-diamino-s-triazine (CAAT)] as well the corresponding mechanistic scheme, observed at the initial stages of photodecomposition of atrazine in POM aqueous solutions, are shown in Scheme 3. Next we have examined the role of various oxidants in the formation and decay of these intermediates. 


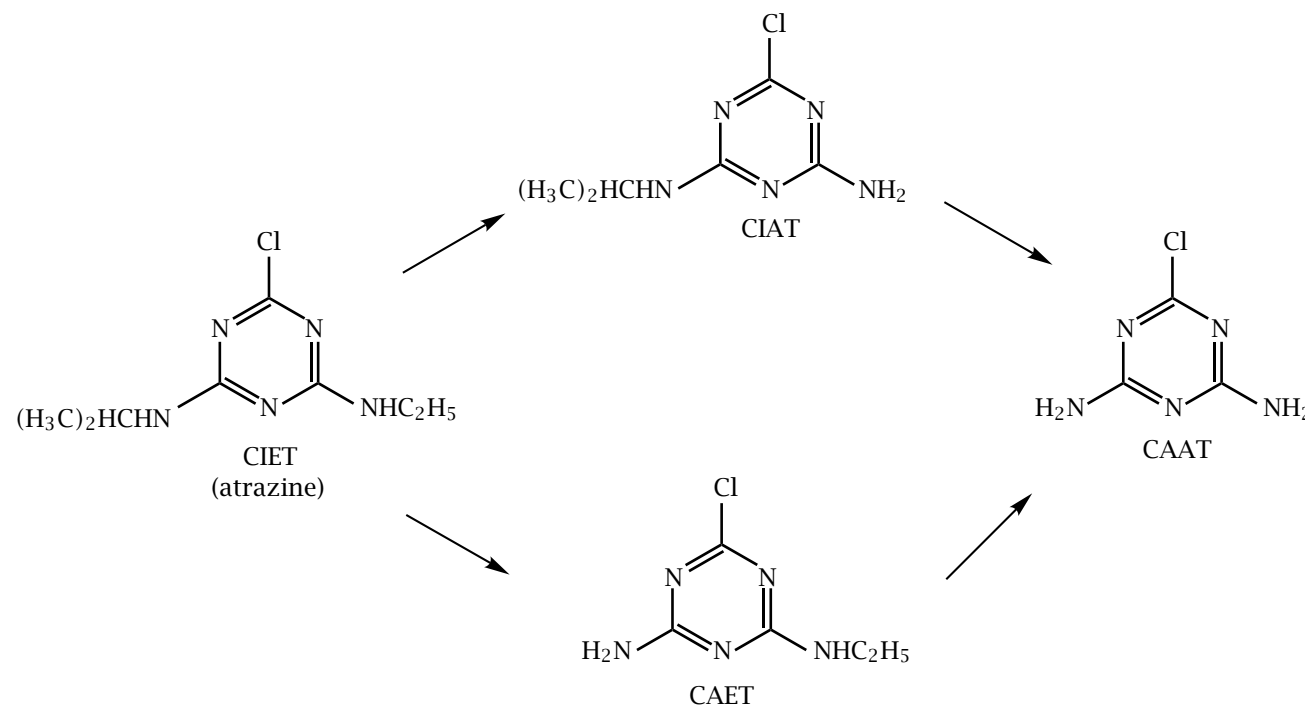

Scheme 3. Degradation pathways (initial stages) for the photocatalytic in the presence of $\mathrm{SiW}_{12} \mathrm{O}_{40}{ }^{4-}$ decomposition of atrazine.

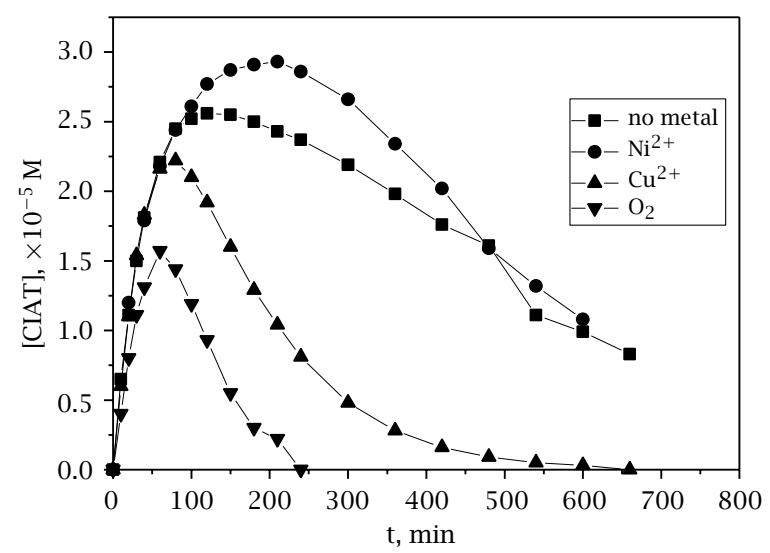

Figure 7. Evolution and decay of the intermediate CIAT during the photocatalytic degradation of atrazine. Experimental conditions as reported in Figure 6.

Figure 7 shows the influence of $\mathrm{Cu}^{2+}, \mathrm{O}_{2}, \mathrm{Ni}^{2+}$ and absence of oxidant in the formation and decay of CIAT, upon photolysis of aqueous solutions of atrazine.

In Figures 8 and 9, the corresponding experiments for CAET and CAAT are exhibited. It should be noted that, under these conditions, no precipitation of metal was observed. The reaction of $\mathrm{Ni}^{2+}$ with $\mathrm{SiW}_{12} \mathrm{O}_{40}{ }^{5-}\left(E^{0}=+0.057 \mathrm{~V}\right)$ is thermodynamically forbidden whereas, the concentration of atrazine is too low to create sufficient concentration of one-equivalent reduced catalyst $\left(\mathrm{SiW}_{12} \mathrm{O}_{40}{ }^{5-}\right)$ and through reaction (6) to cause copper precipitation.

Silver $\left[E^{0}\left(\mathrm{Ag}^{+} / \mathrm{Ag}^{0}\right)=0.799 \mathrm{~V}\right]$ and palladium $\left[E^{0}\left(\mathrm{Pd}^{2+} / \mathrm{Pd}^{0}\right)=0.987 \mathrm{~V}\right.$ vs NHE] whose reduction by tungstosilicate $\left[E^{0}\left(\mathrm{SiW}_{12} \mathrm{O}_{40}{ }^{4-} / \mathrm{SiW}_{12} \mathrm{O}_{40}{ }^{5-}\right)=0.057 \mathrm{~V}\right.$ vs NHE] is thermodynamically permissible, could not

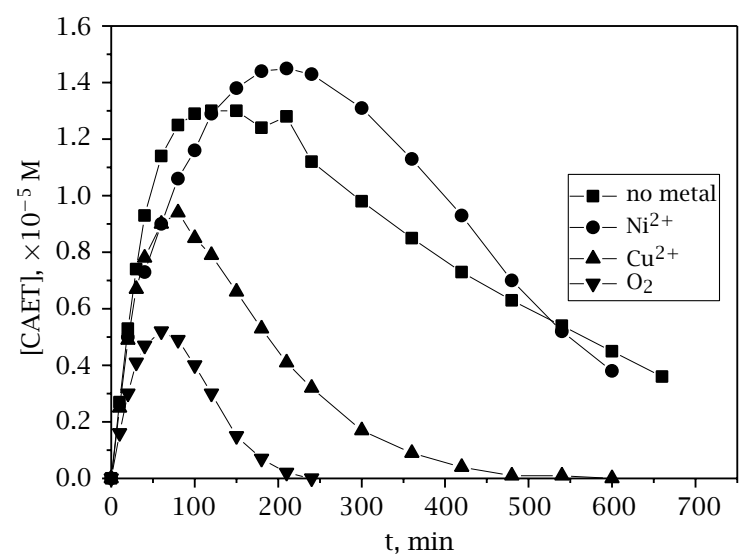

Figure 8. Evolution and decay of the intermediate CAET during the photocatalytic degradation of atrazine. Experimental conditions as reported in Figure 6.

be recovered under these conditions. A cloudy solution was formed upon addition of $\mathrm{AgNO}_{3}$ or $\mathrm{PdCl}_{2}(1.2 \mathrm{mM})$ in an aqueous solution of $\mathrm{SiW}_{12} \mathrm{O}_{40}{ }^{4-}(0.7 \mathrm{mM})$ and atrazine $(0.07 \mathrm{mM})$.

The results suggest that:

- The main degradation pathway involves dealkylation deamination of the side chains of atrazine, followed by dechlorination.

- The reagent used for reoxidation of the catalyst does not influence the nature of the observed intermediates.

- Increasing the oxidizing ability of the catalyst $\left[\mathrm{SiW}_{12} \mathrm{O}_{40}{ }^{4-}>\mathrm{H}_{2} \mathrm{~W}_{12} \mathrm{O}_{40}{ }^{6-}\right]$ increases the rate of photodecomposition of atrazine. 


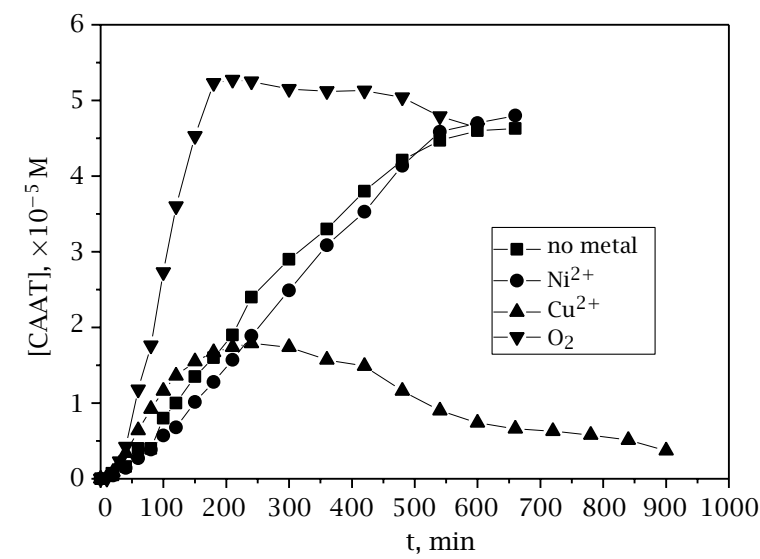

Figure 9. Evolution and decay of the intermediate CAAT during the photocatalytic degradation of atrazine. Experimental conditions as reported in Figure 6.

- Increasing the oxidizing ability of $\mathrm{M}^{\mathrm{n}+}$ $\left[\mathrm{Cu}^{2+}>\mathrm{Ni}^{2+}\right]$ increases the rate of photodecomposition of atrazine.

- No precipitation of metals is observed under these conditions. Reaction of $\mathrm{Ni}^{2+}$ with $\mathrm{SiW}_{12} \mathrm{O}_{40}{ }^{5-}$ is thermodynamically forbidden whereas atrazine concentration is too low
(15 ppm) to cause $\mathrm{Cu}$ removal, as has been observed in other cases.

\section{ACKNOWLEDGEMENTS}

We thank Ministry of Development, General Secretariat of Research and Technology of Greece for supporting part of this work.

\section{References}

[1] E. Papaconstantinou, Chem. Soc. Rev. 16 (1989), 1.

[2] A. Hiskia, A. Mylonas, and E. Papaconstantinou, Chem. Soc. Rev. 30 (2001), 62.

[3] A. Hiskia, E. Androulaki, A. Mylonas, S. Boyatzis, D. Dimotikali, C. Minero, E. Pelizzetti, and E. Papaconstantinou, Res. Chem. Interm. 26 (2000), 235.

[4] A. Hiskia and E. Papaconstantinou, Inorg. Chem. 31 (1992), 163.

[5] A. Troupis, A. Hiskia, and E. Papaconstantinou, New J. Chem. 25 (2001), 361.

[6] A. Hiskia, M. Ecke, A. Troupis, A. Kokorakis, H. Hennig, and E. Papaconstantinou, Environ. Sci. Technol. 35 (2001), 2358. 


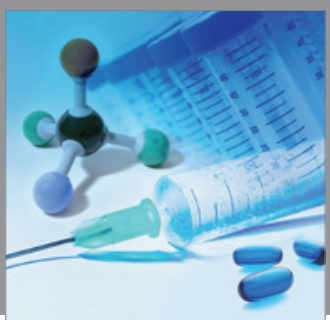

International Journal of

Medicinal Chemistry

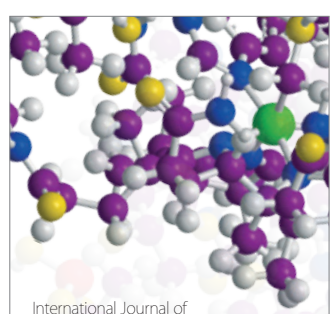

Carbohydrate Chemistry

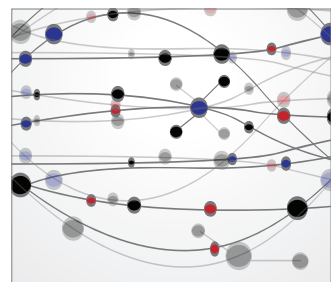

The Scientific World Journal
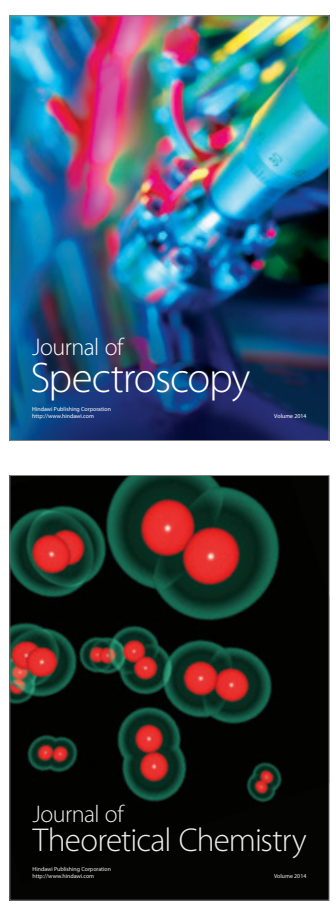
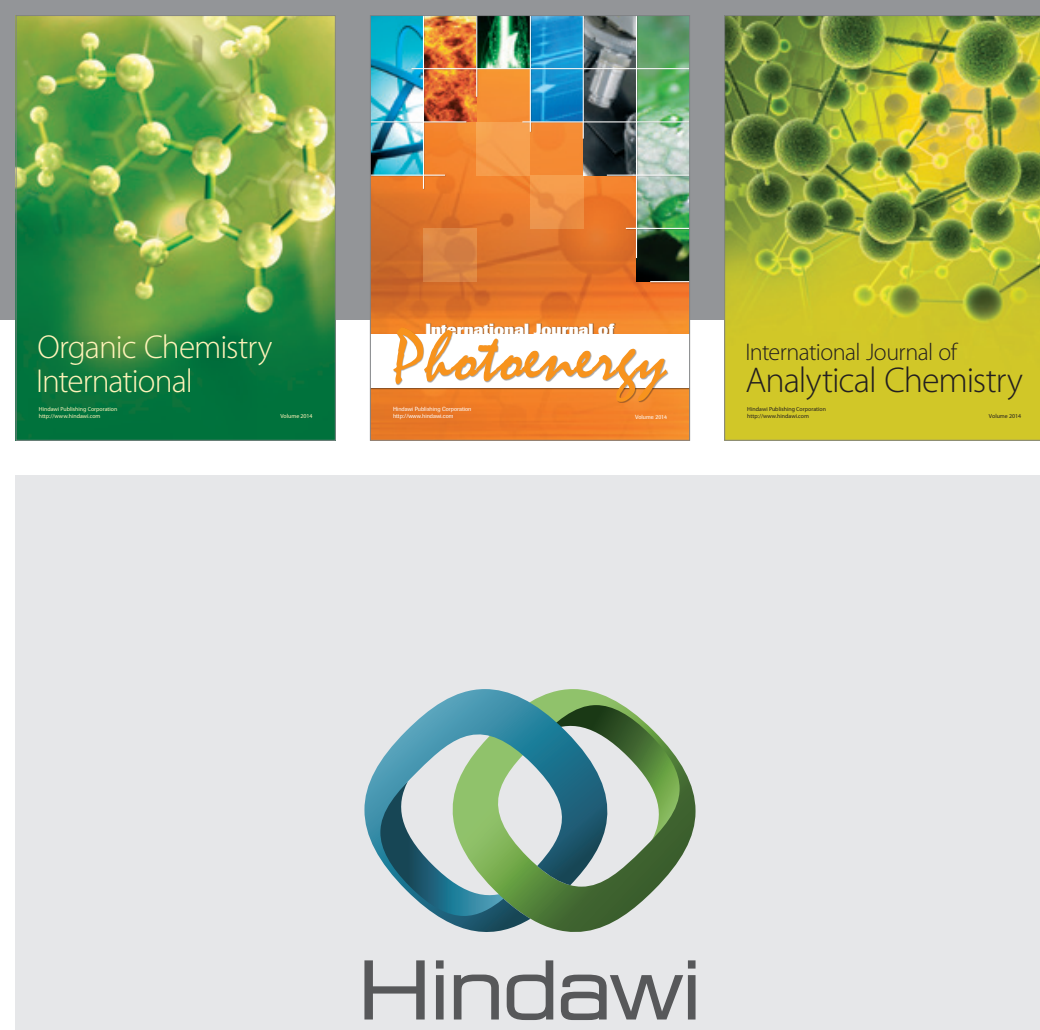

Submit your manuscripts at

http://www.hindawi.com
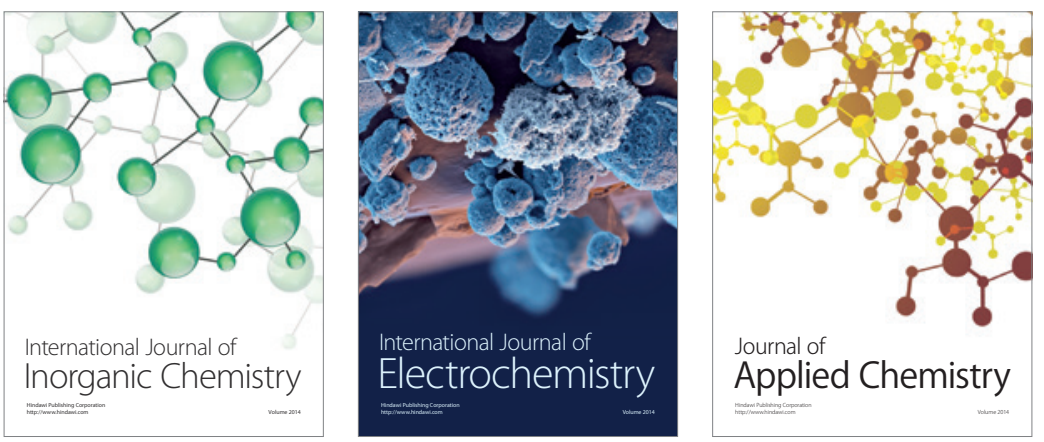

Journal of

Applied Chemistry
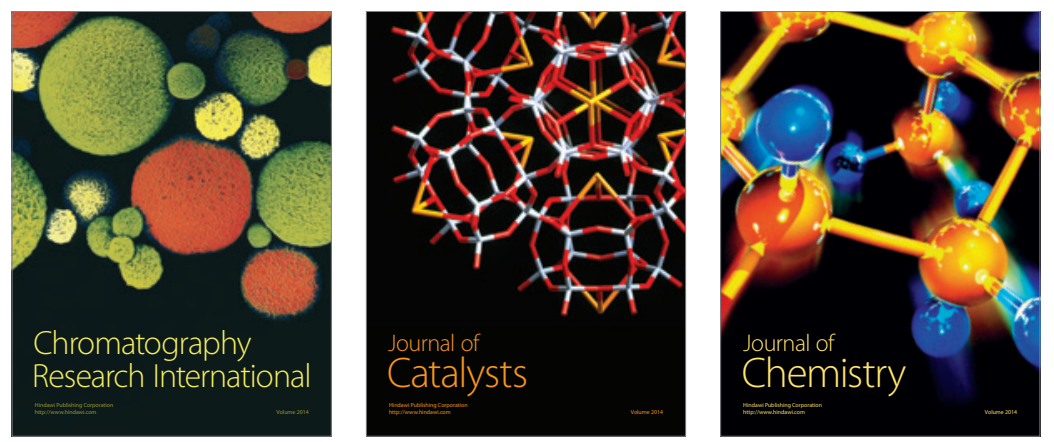
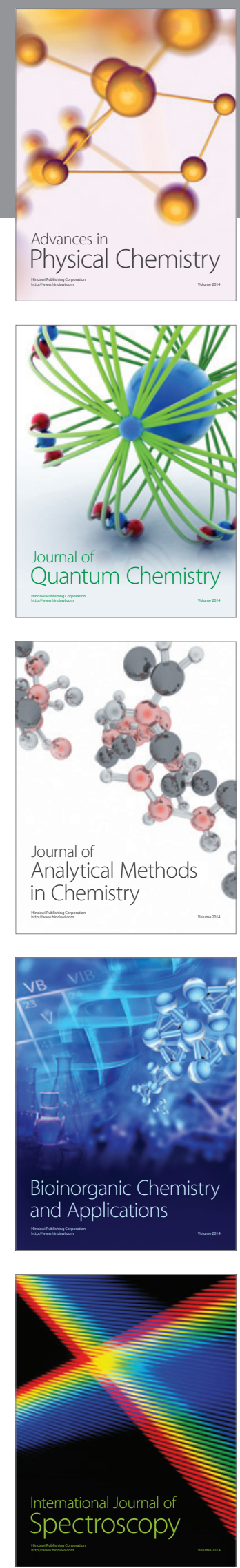